\title{
Comparison of effects of expansionary monetary policy in the Czech Republic and Slovakia
}

\author{
Boris Fisera ${ }^{1}{ }^{*}$, Jana Kotlebova $^{1}$ \\ ${ }^{1}$ University of Economics in Bratislava, Faculty of National Economy, Department of Banking and \\ International Finance, Dolnozemska cesta 1, 85235 Bratislava, Slovakia
}

\begin{abstract}
The ongoing process of globalization has affected the way the monetary policy is conducted - and this is especially the case of small open economies, where the economic developments are heavily affected by the developments abroad. Therefore, the aim of this paper is to investigate the effects of unconventional monetary policy in two very open economies Slovakia and the Czech Republic in the post-crisis era - the two rather similar very open economies. We assess the effects of their monetary policies by estimating their impact on the banking sector in both countries. We employ two cointegrating estimators - DOLS and FMOLS, so that we can assess the dynamics of the relationship between the developments of main balance sheet items of the respective central banks and the aggregate bank lending to various sectors of the economy. We do find evidence that unconventional policies of both central banks did lift bank lending - with the effect being stronger in Slovakia and for the QE policies. In both countries, the effect was more pronounced for the bank lending to household sector - specifically on housing related loans. Finally, we do not find evidence that the increasing openness of these two already very open economies affected the transmission of monetary policies into the banking sector.
\end{abstract}

\section{Introduction}

The Global Financial Crisis (GFC) of 2008-2009 has led to an ultra-loose monetary policy of several of world's major central banks. Central banks have opted for a wide variety of new policy measures - aimed initially to prevent an even more massive slump of the economy and later to boost the economic recovery or prevent deflation. During this period, policy measures implemented by the European Central Bank (ECB) were markedly different to those implemented by the Czech National Bank (CNB). While the ECB relied on policies aimed at providing liquidity to banking system, primarily through its Quantitative Easing (QE) programme, the CNB's main policy measure was the introduction of a one-sided exchange rate commitment, which was defended by sterilised FX interventions. As a result, the primary aim of this paper is to investigate the effects of the ECB's expansionary policies

\footnotetext{
* Corresponding author: boris.fisera@euba.sk
} 
in Slovakia and the effects of the different CNB's policies on the banking sector in the Czech Republic. This analysis is interesting, as both the Czech Republic and Slovakia are rather similar economies - both countries are former transition economies, both joined the European Union (EU) in 2004, both are very open economies, which are characterised by a strong presence of the automotive industry. These similarities also extend into their banking sectors - which are dominated by foreign-owned banks and have historically, especially before the GFC, experienced liquidity surpluses rather than deficits.

The main target of both studied central banks is inflation - both central banks have also repeatedly attributed their expansionary monetary policies to low inflation and/or risk of deflation. However, these policies might impact the inflation through numerous channels. In this article, we aim to concentrate on the impact of these policies on the banking sector specifically on bank lending. For example, the QE, which was by far the most important programme introduced by the ECB in the post-GFC era, may be expected to affect the economy and the bank lending in three ways - the higher bank reserves may motivate the commercial banks to provide more credit, furthermore, higher asset prices might also lead to higher bank equity and thus stimulate higher bank lending. Finally, higher bond prices caused by the QE may lead to changes in relative prices of assets - thus requiring a new optimal portfolio allocation - with higher proportion of relatively longer-term and higher-yielding assets, which may include loans [1]. Through these channels, the ECB's policy might be expected to lead to higher bank lending, higher investments and economic growth and eventually to higher inflation. The QE might also increase inflation expectations and thus contribute to attaining ECB's inflation target. On the other hand, the CNB's one-sided exchange rate commitment was introduced to increase inflation via higher import prices and increase economic growth through higher competitiveness of domestic economy - with higher growth eventually leading to higher inflation. The policy can also be expected to raise the inflation expectations [2]. The possibility of using a managed depreciation to increase inflation rate and escape the deflation trap, when the conventional policy options can no longer be used to ease monetary conditions, has already been discussed at the turn of the millennium - due to economic stagnation in Japan. For example, [3] concluded that even at the Zero Lower Bound (ZLB), there is a possibility for monetary authorities to prevent deflation - by using foreign exchange operations to weaken the domestic currency.

As the ECB's unconventional monetary policy was aimed primarily at increasing bank lending, in this paper, we intend to investigate the effects of the unconventional monetary policy on the banking sector. Indeed, the National Bank of Slovakia (NBS) has recently been voicing concerns about the rapid growth of private sector debt in Slovakia [4] - consequently, we aim to investigate, to which extent did ECB's unconventional policies such as QE contribute to this development. Furthermore, as the Czech economy is rather similar to Slovak economy, we aim to investigate the effect of CNB's one-sided exchange rate commitment on Czech banking sector and compare the varied effects of these two expansionary monetary policies.

Our paper therefore follows two strands of literature - studies, which analysed the effects of unconventional monetary policies in general, as well as studies, which analysed the effect of monetary policies on bank lending. The rest of the paper is structured as follows: next section is dedicated to literature review, the third section describes the data used, as well as the empirical methodology. Fourth section presents the results and fifth section concludes the paper. 


\section{Literature review}

There is a growing body of literature, which focuses on the effects of unconventional monetary policies in the post-crisis era. However, most studies have concentrated on the effects of unconventional policies on inflation or on other macroeconomic variables. Among the unconventional policies, most papers focus on QE. These papers usually find that these policies did have a positive effect on inflation and on output - though they mostly do not empirically investigate, which transmission channels contributed most to these positive effects. An early example of such a study is [5], who use a BVAR model and find that nonstandard measures that the ECB implemented during the crisis had positive impact on output and inflation. However, these effects only appeared with a lag. [6] focused on the analysis of macroeconomic effects of 3-year LTROs introduced by the ECB - their results indicated that LTROs contributed positively to prices in the Euro Area. [7] found using a DSGE model that the ECB's QE raised both inflation and inflation expectations. [8]'s findings also confirm a positive relationship between the QE and inflation - in consensus with other studies. Their analysis using a BVAR found that an announcement of a QE worth $1 \%$ of GDP raised inflation in the US and UK by $0.62 \%$ and $0.32 \%$, respectively.

Main strand of literature that we follow in this paper is the literature that focuses on the effects of unconventional monetary policy on bank lending. The number of studies dedicated to this issue is, however, rather limited. For example, [9] focused on the effects of two very long-term refinancing operations (VLTRO) on credit supply in Spain and they found that these VLTROs had a moderately positive effect, which was driven by illiquid banks and by credit to SMEs. [10] used a SVAR model to examine the relationship between the unconventional monetary policy and bank lending and found that the unconventional monetary policy did not boost the bank lending very significantly. On the other hand, [11] studied the effect of ECB's QE on bank lending in Slovakia. Using bank-level data, she concluded that the QE did boost the bank lending - more so for the households than for firms. [12] examined the impact of expansionary balance sheet shock of the ECB. They found that such a shock indeed does increase bank lending, depresses interest rate spreads, weakens the Euro and raises both economic growth and inflation. Looser lending standards of banks were found to have contributed more to increased credit provision than the loan demand. Furthermore, the positive effects of expansionary monetary policies were more pronounced in member states with more capitalized banking systems. [13] found that unconventional monetary policy in the Eurozone had a positive and lagged impact on bank credit - this effect was much stronger for bank credit to general government at $1.2 \%$ monthly, than for the bank credit to households, which was up by only about $0.2 \%$ monthly. [14] used country-specific data for the Euro Area countries and concluded that the increased liquidity provided by the ECB did boost the loan demand, loan supply and to lesser extent economic growth.

Further contribution of our paper is the analysis of the effects of CNB's policy of onesided exchange rate commitment enforced by FX interventions on banking sector. Indeed the literature, which studies the effect of FX interventions on bank lending, is even scarcer. One example is [15], who used high-frequency data to study the effect of sterilized purchases of U.S. dollars by Colombian central bank and found that these interventions damped credit growth. This study concluded that by slowing down the appreciation of domestic currency, the FX interventions may slow down the credit growth caused by capital inflow surges. Further studies have concentrated on the crowding out effects of FX interventions, whereby the supply of securities issued by the central bank to sterilize the FX purchases reduces the bank lending capacity - as large volume of these securities needs to be absorbed by the banks. [16]'s findings provided some support for this view in the case of emerging economies from Eastern and South Eastern Asia. Nevertheless, [17] found that for healthier banking systems, even sterilized FX interventions lead to higher bank credit to private sector - with this effect 
being stronger over the long-term. Their findings support an alternative view of the relationship between the FX reserves and bank credit provision. This view emphasized that since there is some degree of substitutability between the liquid securities issued by the central bank and excess reserves, the banks may use their securities holdings to provide more credit to the private sector [18].

\section{Data and empirical strategy}

In the following section, we discuss the data used for the purpose of this research, as well as the empirical methodology.

\subsection{Data}

We rely on monthly data and we focus primarily on the crisis and the post-crisis period. As a result, in baseline regressions, our sample covers the period between the years 2009 and 2018. We selected this period so that we have uniform sample for both the countries, which enables easier comparison between the two countries. However, as the monetary policy in the Czech Republic and in Slovakia was not synchronized, we also re-run our regressions on only those periods, when each of the central banks conducted its most important unconventional policy operations. In this sub-sample, we concentrate on the years 2015-2018 for Slovakia, as this was the period when the ECB was implementing the QE, its largest unconventional policy operation. Conversely, for the Czech Republic, we focus on a subsample for the period between November 2013 and April 2017, as this was the time of CNB's one-sided exchange rate commitment. To save space, we do not report these results here the results obtained from this sub-sample broadly support our baseline findings.

The primary sources of our data are the respective central banks. As our dependent variable, we use a measure of bank lending. As our measure of bank lending, we use total bank loans to their customers in billions of respective national currencies. Furthermore, we also examine the transmission of unconventional measures into bank lending to two main economic sectors of interest - households and non-financial corporations (NFCs), as well as the transmission of unconventional policy measures to loans of different maturities by separately studying their effects on bank loans with different maturities. As our main explanatory variable, we use a measure of unconventional monetary policy - for this purpose, we use the available data from both the NBS and CNB. For Slovakia, as NBS does not publish data on its monthly securities purchases, we use the NBS' holdings of public sector securities as an indicator of Public Securities Purchase Program (PSPP) ${ }^{2}$, while we also use the volume NBS' loans to commercial banks as a measure of other expansionary operations (for example the TLTROs or LTROs). Moreover, to control for other factors that affect the bank lending, we include following explanatory variables into our model for Slovakia: industrial production index, which we use as a proxy for economic performance and the economic sentiment indicator, which might affect the banks' decisions on credit provisions or firms' and households' decisions to apply for loans. For the Czech Republic, we eventually decided to limit our analysis to only the effect of CNB's FX purchases on banking sector - as the CNB's assets consist of almost exclusively the FX reserves, while the remaining policy operations performed during the immediate post-GFC era seem to have been of only very limited scope. Consequently, for the Czech Republic, our explanatory variable is represented by CNB's holdings of FX reserves, which serves as a proxy for CNB's FX interventions. As control variables, we include the following variables into the Czech model: industrial production as

${ }^{2}$ PSPP programme represents by far the portion of the ECB's QE purchases. 
a proxy for output, and the economic sentiment indicator. All the variables that represent bank lending or unconventional monetary policies are in billions of respective national currencies and in our regressions, these variables are expressed as logarithms. Finally, we also include interest rate to our regressions to control for the effect of lower interest rates on bank credit. As the central bank policy rates remained constant for most of the analyzed period, we decided to use overnight interbank rates as a proxy for policy interest rates. We therefore include the Eonia interbank rate into the regressions for Slovakia, while we include the overnight Pribor rate into the regressions for the Czech Republic ${ }^{3}$.

\subsection{Empirical strategy}

To analyze the relationship between the unconventional policies and the commercial bank loans to the economy, we opted to use two cointegrating estimators - Fully-modified OLS (FMOLS) and Dynamic OLS (DOLS) to control for the non-stationarity of the time series included into our analysis. These estimators examine the long-run relationship between the dependent and independent variables. DOLS approach was initially discussed by [19] and later further developed by [20]. DOLS estimator corrects for non-stationarity of the variables by including leads and lags of the differences of independent variable into the model - the approach rests on the assumption that the leads and lags will control for trend in the regression. FMOLS estimator was first proposed by [21] and further extended by [22]. This estimator uses a semi-parametric correction to correct the non-stationarity of the variables. Our main model can be described as follows:

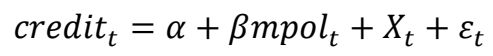

where credit is the measure of commercial bank lending, while mpol is the measure of unconventional monetary policy. Finally, $X$ is a vector of economy-wide variables that we include to control for other factors that might influence bank lending.

Before proceeding with the estimation, we perform the unit root tests to test the order of integration of the variables including into the models - we rely on ADF test and the results of the tests indicated that all the variables included into our models are integrated of order one I(1), i.e. all the variables are non-stationary. As our preferred test of cointegration, we use the Johansen Cointegration Test - we do not report the results of these tests here to save space, however, the results are available from authors upon request. Number of lags for the cointegration tests was selected based on the Schwarz Information Criterion.

\section{Results}

In this next section we present the results of our estimations. We focus on the results from our baseline sample, which covers the entire period from the beginning of the year 2009, i.e. the year when the GFC hit both studied economies, until the end of the year 2018. For this baseline sample, we study the relationship between our selected measures of unconventional policies (i.e. the central bank loans to commercial banks, or central bank holdings of public sector securities, or FX reserves) and the measures of bank lending.

Our results for Slovakia, which are reported in Table 1 in the Appendix indicate that both public securities purchases and the central bank credit provisions to the commercial banks did have a positive effect on the total bank loans to their private, non-financial customers.

\footnotetext{
${ }^{3}$ We are aware of possible causality issues associated with using the overnight interbank rates as a proxy for interest rate - as these interbank rates themselves might be affected by monetary policy actions. Consequently, as a robustness check, we estimated all our regressions without the interest rate and found that the inclusion of the interest rate variables does not influence our main findings.
} 
Each of the model specifications is estimated using both the DOLS and FMOLS estimators. Based on our results, we may conclude that the central bank purchases of public securities had a stronger impact on credit provision than central bank loans to the commercial banks. Additionally, as all the coefficients are below 1, we may conclude that the Slovak banks did not use all the resources they received from the NBS to increase credit to the economy which could help to explain the rising amounts of commercial banks' deposits in the NBS. We also find that the impact of monetary policy was stronger for the loans to the households sector - especially for the housing-related loans. These results are also driven primarily by the central bank's purchases of public securities. The stronger impact on the housing-related loans may be explained by higher responsiveness of this type of loans to interest costs - under the conditions of record-low interest rates and rather stable economic environment, the households seem to have increased their demand for housing-related loans significantly and the banks were willing to use the resources provided to them by the NBS to fund these loans. On the other hand, the central bank credit to commercial banks seems to have had a stronger effect on non-housing loans to households and on the credit to NFCs than on housing-related loans - which can be explained by the fact that some of the policy operations (such as Targeted long term operations ${ }^{4}$ ) were targeted specifically at these types of loans. Nevertheless, even for this category of loans, the QE had stronger effect than the central bank credit provisions. We also found that the expansionary policies had a negative effect on shortterm loans to $\mathrm{NFCs}^{5}$ - indicating that the banks were less interested in using the newly obtained resources to fund the short-term loans and they rather focused on long-term loans as evidenced by higher coefficients of our explanatory variables on this category of loans.

Table 2 in the Appendix reports the results for the Czech Republic. These results also indicate that the expansionary central bank policies, represented by FX interventions, did lift the bank lending in the Czech Republic. However, the effect is much less pronounced in the Czech Republic when compared to Slovakia. This outcome is hardly surprising, as the unconventional monetary policy of the Eurosystem was intended specifically to operate through the banking sector, which was not the case for the Czech Republic, where any effect of CNB's policies on bank lending could only be secondary. The monetary policy's effect on various types of loans in the Czech Republic seems to follow a pattern similar to Slovakia with strongest effect on housing-related loans and on longer-term loans to NFCs. The impact of expansionary policies is negligible for short-term loans to NFCs and rather small for nonhousing loans to households.

Finally, both the Czech Republic and Slovakia are very open economies - and this openness increased even further during the studied era. Indeed, based on the data from CNB and NBS, the proportion of exports and imports to GDP increased from approximately $90 \%$ to almost $130 \%$ of Czech GDP between 2009 and 2018, while for Slovakia, this ratio increased from more than $120 \%$ to more than $170 \%$ over the corresponding period. As a result, we aim to investigate, whether this increased openness affected the transmission of expansionary monetary policies into the banking sector. To this end, we follow the approach taken by [23] and we introduce an interaction term into our regressions. This interaction term interacts the openness of the economy, measured as a ratio of foreign trade to GDP, and one of our measures of expansionary monetary policies. The results are reported in Table 3 , where we only use the total amount of outstanding loans to the economy as our dependent variable and include interaction terms for each of the three analyzed expansionary policies ${ }^{6}$. The

\footnotetext{
4 TLTROs could not be used to fund housing loans with maturity of more than 2 years.

${ }^{5}$ Loans with a maturity of up to one year.

${ }^{6}$ In the case of regressions with interaction term, we have centered the dependent and explanatory variables (with mean being set to zero) in order to reduce the problems posed by multicollinearity.
} 
regressions in Table 3 were only estimated with DOLS estimator. However, the results indicate that the increasing openness did not affect the transmission of monetary policies into the banking sector in either the Czech Republic or in Slovakia - as the coefficients for all the interaction terms for all our measures of unconventional policies are not statistically significant at $5 \%$ significance level.

Table 3. Effect of unconventional monetary policies on total bank loans - including interaction terms

\begin{tabular}{|c|c|c|}
\hline & (1) & (2) \\
\hline VARIABLES & \multicolumn{2}{|c|}{ Total loans } \\
\hline Country & Czech Republic & Slovakia \\
\hline Central Bank External Assets & $0.387 * * *$ & \\
\hline Public Sector Securities & & 0.970 \\
\hline Loans to EA Resident MFIs & & 0.189 \\
\hline Interaction Openness and CB External Assets & -0.009 & \\
\hline Interaction Openness and QE & & $9.157 *$ \\
\hline Interaction Openness and CB Loans & & -0.258 \\
\hline Openness & 1.663 & $30.738^{*}$ \\
\hline Observations & 117 & 117 \\
\hline R-squared & 0.969 & 0.946 \\
\hline
\end{tabular}

$*$ denotes 10 percent significance level, $* * 5$ percent significance level, $* * * 1$ percent significance level.

\section{Conclusions}

In this paper, we use monthly data from the crisis and post-crisis era for the Czech Republic and Slovakia to examine the effect of unconventional monetary policies conducted by the respective central banks on the banking sector. We use two cointegrating estimators - DOLS and FMOLS to investigate this relationship. We found that for Slovakia, the ECB's QE program had a more significant and positive effect on bank lending than the provisions of NBS' loans to commercial banks. We did find a positive effect of CNB's policy of exchange rate commitment coupled with FX interventions on bank loans in the Czech Republic. However, this effect was rather limited and much less pronounced when compared to Slovakia. Nevertheless, we did find evidence that the banks in both countries increased their loan provision to a lesser extent than the overall amount of liquidity injected to the economy by the respective central banks. Our findings are therefore in line with the previous literature, which finds that for more capitalized banking systems, the expansionary policies normally boost bank lending. Our findings for the Czech Republic also reinforce the view that for the healthier banking systems, the FX interventions against the domestic currency may have positive effect on bank lending. Furthermore, while especially for the ECB's loan provision programs, such as the TLTRO, the primary goal was to boost bank lending to firms or nonhousing lending to households and by doing so increase investments, we find that both this program and the QE, boosted primarily the housing-related lending in Slovakia. At the same time, the impact of the unconventional policies on bank lending to firms was rather less pronounced. The findings were rather similar for the Czech Republic. Consequently, we conclude that while unconventional policies did lead to increased bank lending in both countries, they mostly increased housing-related credit that had already been growing rapidly in both countries, thus contributing to higher household debt that may pose as a potential risk for financial stability in the future. Besides, the unconventional policies did not lift the lending to firms substantially and thus do not seem to have led to significantly higher private sector investments - as a result, the overall long-term positive effect of these policies is likely to be limited. Finally, we also investigated whether the increasing openness of both the Czech 
Republic and Slovakia affected the effectiveness of the transmission of the respective central banks policies into the banking sector. However, our findings tentatively suggest that the increasing openness of these two economies do not seems to have affected the effectiveness of transmission of monetary policy actions. Thus supporting the notion that even in the increasingly globalized and interconnected world, the central banks are still capable of influencing the economy in order to achieve their goals.

The authors acknowledge that this paper is the partial result of the project VEGA (1/0613/18) Deepening of Economic Inequalities as a Consequence of Distributional Effects of Unconventional Monetary Policy.

\section{References}

1. J. Tischer, Quantitative easing, portfolio rebalancing and credit growth: Micro evidence from Germany. Discussion Paper 20, Deutsche Bundesbank (2018)

2. M. Skorepa, M. Tomsik, J. Vlcek, Impact of the CNB's exchange rate commitment: Pass-through to inflation. BIS Paper, 89, Bank for International Settlements (2016)

3. B. T. McCallum, Theoretical analysis regarding a zero lower bound on Nominal interest rates. NBER Working Paper, 7677, National Bureau of Economic Research (2019)

4. NBS (2018). Financial Stability Report November 2018. National Bank of Slovakia.

5. M. Lenza et al., Monetary policy in exceptional times. Economic Policy, 25 (62), 295 339 (2010)

6. M. Darracq-Paries, R. A. De Santis, A non-standard monetary policy shock: The ECB's 3-year LTROs and the shift in credit supply. Journal of International Money and Finance, 54, 1-34 (2015)

7. P. Andrade et al., The ECB's asset purchase programme: An early assessment. ECB Working Paper, 1956, European Central Bank (2016)

8. M. Weale, M. Wieladek, What are the macroeconomic effects of asset purchases. Journal of Monetary Economics, 79, 81-93 (2016)

9. M. Garcia-Posada, M. Marchetti, The bank lending channel of unconventional monetary policy: The impact of VLTROs on credit supply in Spain. Economic Modelling, 58, 427441 (2016)

10. S. Behrendt, Unconventional monetary policy effects on bank lending in Euro Area. Jena Economic Research Papers, 2017-002, Friedrich Schiller University Jena (2017)

11. A. Lojschova, Did quantitative easing boost bank lending? The Slovak experience. NBS Working Paper, 1/2017, National Bank of Slovakia (2017)

12. J. Boeckx et al., Effectiveness and transmission of the ECB's balance sheet policies. International Journal of Central Banking, 13 (1), 297-333 (2017)

13. L. F. Martins, J. Batista, A. Ferreira-Lopes, Unconventional monetary policies and bank credit in the Eurozone: An events study approach. International Journal of Finance \& Economics, 2018, 1-15 (2018)

14. M. Guth, Heterogeneous Effects of Unconventional Monetary Policy on Loan Demand and Supply. Insights from the Bank Lending Survey. ArXiv.org Papers, 1807.04161, Cornell University (2018)

15. B. Hofmann et al., FX intervention and domestic credit: Evidence from high-frequency micro data. BIS Working Papers, 774, Bank for International Settlements. (2019) 
16. D. Cook, J. Yetman, Expanding central bank balance sheets in emerging Asia: A Compendium of Risks and Some Evidence. BIS Papers, 66, pp. 30-75 (2012)

17. B. Gadanecz et al., Foreign exchange intervention and the banking system balance sheet in emerging market economies. BIS Working Papers, 445, Bank for International Settlements (2014)

18. T. Jokipii, A. Milne, Bank capital buffer and risk adjustment decisions. Journal of Financial Stability, 7 (3), 165-178 (2011)

19. P. Saikkonen, Asymptotically efficient estimation of cointegration regressions. Economic Theory, 7 (1), 1-21 (1991)

20. J. H. Stock, M. W. Watson, A simple estimator of cointegrating vectors in higher order integrated systems. Econometrica, 61 (4), 783-820 (1993)

21. P. C. B. Phillips, B. E. Hansen, Statistical inference in instrumental variables regression with I(1) processes. The Review of Economic Studies, 57 (1), 99-125 (1990)

22. P. C. B. Phillips, H. R. Moon, Linear regression limit theory for nonstationary panel data. Econometrica, 67 (5), 1057-1111 (1999)

23. R. Horvath et al., Interest rate pass-through in the Euro Area: Financial fragmentation, balance sheet policies and negative rates. Journal of Financial Stability, 36 (C), 12-21 (2018) 
Appendix

Table 1. The effect of unconventional monetary policies on bank loans in Slovakia (2009-2018)

\begin{tabular}{|c|c|c|c|c|c|c|c|c|}
\hline \multirow{3}{*}{$\begin{array}{l}\text { VARIABLES } \\
\text { Estimator }\end{array}$} & (1) & (2) & (3) & (4) & (5) & (6) & (7) & (8) \\
\hline & \multicolumn{2}{|c|}{ Total loans } & \multicolumn{2}{|c|}{ Loans to households } & \multicolumn{2}{|c|}{ Loans to households - housing } & \multicolumn{2}{|c|}{$\begin{array}{c}\text { Loans to households - non- } \\
\text { housing }\end{array}$} \\
\hline & FMOLS & DOLS & FMOLS & DOLS & FMOLS & DOLS & FMOLS & DOLS \\
\hline \multirow[t]{2}{*}{ Public Sector Securities } & $0.931 * * *$ & $0.794 * * *$ & $0.673 * * *$ & $0.506 * * *$ & $0.481 * * *$ & $0.333^{* *}$ & $0.073 * * *$ & $0.060 * * *$ \\
\hline & $(0.211)$ & $(0.261)$ & $(0.179)$ & $(0.170)$ & $(0.152)$ & $(0.147)$ & $(0.023)$ & $(0.009)$ \\
\hline \multirow[t]{2}{*}{ Loans to EA Resident MFIs } & $0.220 * *$ & 0.182 & $0.157^{*}$ & 0.128 & 0.113 & 0.085 & $0.032 * * *$ & $0.028 * * *$ \\
\hline & $(0.099)$ & $(0.134)$ & $(0.083)$ & $(0.087)$ & $(0.071)$ & $(0.075)$ & $(0.011)$ & $(0.005)$ \\
\hline \multirow[t]{2}{*}{ Output } & $0.473 * * *$ & $0.533 * * *$ & $0.397 * * *$ & $0.460 * * *$ & $0.350 * * *$ & $0.408 * * *$ & $0.096 * * *$ & $0.106 * * *$ \\
\hline & $(0.080)$ & $(0.124)$ & $(0.068)$ & $(0.081)$ & $(0.058)$ & $(0.070)$ & $(0.009)$ & $(0.004)$ \\
\hline \multirow[t]{2}{*}{ Economic Sentiment Indicator } & -0.039 & -0.046 & -0.022 & -0.036 & -0.027 & -0.040 & 0.005 & 0.002 \\
\hline & $(0.054)$ & $(0.085)$ & $(0.046)$ & $(0.056)$ & $(0.039)$ & $(0.048)$ & $(0.006)$ & $(0.003)$ \\
\hline \multirow{2}{*}{ Interest Rate } & -1.131 & -0.675 & $-2.105^{* *}$ & -1.611 & $-1.863^{* *}$ & -1.385 & -0.180 & -0.037 \\
\hline & (1.239) & (1.724) & $(1.050)$ & (1.126) & $(0.894)$ & $(0.974)$ & $(0.133)$ & $(0.062)$ \\
\hline \multirow[t]{2}{*}{ Constant } & -5.722 & -9.934 & $-16.331 * * *$ & $-20.048 * * *$ & $-16.127 * * *$ & $-19.686 * * *$ & $-5.837 * * *$ & $-6.409 * * *$ \\
\hline & $(5.298)$ & $(7.811)$ & $(4.490)$ & $(5.104)$ & $(3.823)$ & $(4.413)$ & $(0.570)$ & $(0.279)$ \\
\hline Observations & 119 & 117 & 119 & 117 & 119 & 117 & 119 & 117 \\
\hline R-squared & 0.945 & 0.977 & 0.942 & 0.981 & 0.945 & 0.981 & 0.951 & 0.984 \\
\hline \multirow[b]{2}{*}{ VARIABLES } & (9) & $(10)$ & $(11)$ & $(12)$ & (13) & $(14)$ & $(15)$ & $(16)$ \\
\hline & \multicolumn{2}{|c|}{ Loans to nonfinancial corporations } & \multicolumn{2}{|c|}{$\begin{array}{l}\text { Loans to nonfinancial } \\
\text { corporations - short-term }\end{array}$} & \multicolumn{2}{|c|}{$\begin{array}{c}\text { Loans to nonfinancial } \\
\text { corporations }- \text { medium-term }\end{array}$} & \multicolumn{2}{|c|}{$\begin{array}{c}\text { Loans to nonfinancial corporations - } \\
\text { long-term }\end{array}$} \\
\hline Estimator & FMOLS & DOLS & FMOLS & DOLS & FMOLS & DOLS & FMOLS & DOLS \\
\hline \multirow[t]{2}{*}{ Public Sector Securities } & $0.229 * * *$ & $0.200 * * *$ & $-0.054 * * *$ & $-0.061 * * *$ & $0.080 * * *$ & $0.073 * * *$ & $0.205 * * *$ & $0.188 * * *$ \\
\hline & $(0.043)$ & $(0.018)$ & $(0.016)$ & $(0.017)$ & $(0.023)$ & $(0.017)$ & $(0.024)$ & $(0.009)$ \\
\hline \multirow[t]{2}{*}{ Loans to EA Resident MFIs } & $0.070 * * *$ & $0.049 * * *$ & 0.010 & 0.003 & $0.028 * * *$ & $0.025 * * *$ & $0.031 * * *$ & $0.021 * * *$ \\
\hline & $(0.020)$ & $(0.009)$ & $(0.007)$ & $(0.009)$ & $(0.011)$ & $(0.008)$ & $(0.011)$ & $(0.005)$ \\
\hline \multirow[t]{2}{*}{ Output } & $0.069 * * *$ & $0.086 * * *$ & $0.038 * * *$ & $0.050 * * *$ & $-0.019 * *$ & $-0.019 * *$ & $0.049 * * *$ & $0.055 * * *$ \\
\hline & $(0.016)$ & $(0.009)$ & $(0.006)$ & (0.008) & $(0.009)$ & $(0.008)$ & $(0.009)$ & $(0.004)$ \\
\hline \multirow[t]{2}{*}{ Economic Sentiment Indicator } & -0.007 & -0.008 & $-0.027 * * *$ & $-0.032 * * *$ & $0.018 * * *$ & $0.022 * * *$ & 0.002 & 0.002 \\
\hline & $(0.011)$ & $(0.006)$ & $(0.004)$ & $(0.006)$ & $(0.006)$ & $(0.005)$ & $(0.006)$ & $(0.003)$ \\
\hline \multirow[t]{2}{*}{ Interest Rate } & $0.781 * * *$ & $0.939 * * *$ & $0.297 * * *$ & $0.441 * * *$ & -0.012 & -0.016 & $0.485 * * *$ & $0.514 * * *$ \\
\hline & $(0.252)$ & $(0.121)$ & $(0.094)$ & $(0.112)$ & $(0.136)$ & $(0.110)$ & $(0.143)$ & (0.059) \\
\hline \multirow[t]{2}{*}{ Constant } & $9.245^{* * * *}$ & $7.993 * * *$ & $4.907 * * *$ & $4.299 * * *$ & $3.505 * * *$ & $3.186 * * *$ & 0.899 & $0.509 *$ \\
\hline & $(1.078)$ & $(0.549)$ & $(0.400)$ & $(0.508)$ & $(0.580)$ & $(0.497)$ & $(0.610)$ & $(0.269)$ \\
\hline Observations & 119 & 117 & 119 & 117 & 119 & 117 & 119 & 117 \\
\hline R-squared & 0.848 & 0.936 & 0.268 & 0.641 & 0.365 & 0.574 & 0.875 & 0.965 \\
\hline
\end{tabular}

Standard errors are in parentheses. $*$ denotes 10 percent significance level, $* *$ denotes 5 percent significance level, $* * *$ denotes 1 percent significance level. 
Table 2. The effect of unconventional monetary policies on bank loans in the Czech Republic (2009-2018)

\begin{tabular}{|c|c|c|c|c|c|c|c|c|}
\hline \multirow{3}{*}{$\begin{array}{l}\text { VARIABLES } \\
\text { Estimator }\end{array}$} & (1) & (2) & (3) & (4) & (5) & (6) & (7) & (8) \\
\hline & \multicolumn{2}{|c|}{ Total loans } & \multicolumn{2}{|c|}{ Loans to households } & \multicolumn{2}{|c|}{ Loans to households - housing } & \multicolumn{2}{|c|}{ Loans to households - non-housing } \\
\hline & FMOLS & DOLS & FMOLS & DOLS & FMOLS & DOLS & FMOLS & DOLS \\
\hline \multirow[t]{2}{*}{ Central Bank External Assets } & $0.305^{* * *}$ & $0.245^{* * *}$ & $0.164 * * *$ & $0.138 * * *$ & $0.138 * * *$ & $0.116 * * *$ & $0.025 * * *$ & $0.022 * * *$ \\
\hline & $(0.041)$ & $(0.028)$ & $(0.024)$ & $(0.019)$ & $(0.018)$ & $(0.014)$ & $(0.006)$ & $(0.006)$ \\
\hline \multirow[t]{2}{*}{ Output } & $-10.502 * * *$ & $-15.867 * * *$ & -2.329 & $-4.164 *$ & -2.341 & $-4.372 * * *$ & 0.167 & 0.208 \\
\hline & $(4.027)$ & $(3.232)$ & $(2.360)$ & $(2.127)$ & $(1.788)$ & $(1.590)$ & $(0.612)$ & $(0.693)$ \\
\hline \multirow[t]{2}{*}{ Economic Sentiment Indicator } & $13.429 * *$ & $17.097 * * *$ & $6.034 *$ & $5.814 * *$ & $5.110 * *$ & $5.509 * * *$ & 1.066 & 0.305 \\
\hline & $(5.780)$ & $(4.202)$ & $(3.387)$ & $(2.765)$ & $(2.567)$ & $(2.067)$ & $(0.879)$ & $(0.900)$ \\
\hline \multirow[t]{2}{*}{ Interest Rate } & $-166.948 * * *$ & $-179.513^{* * * *}$ & $-83.669 * * *$ & $-94.953 * * *$ & $-60.555^{* * *}$ & $-69.806 * * *$ & $-20.691 * * *$ & $-25.146 * * *$ \\
\hline & $(50.497)$ & $(30.750)$ & $(29.593)$ & $(20.235)$ & $(22.426)$ & $(15.127)$ & $(7.678)$ & $(6.589)$ \\
\hline \multirow[t]{2}{*}{ Constant } & $1,972.234 * * *$ & $2,250.416^{* * *}$ & $667.357 * * *$ & $917.418 * * *$ & $453.800 * *$ & $658.405 * * *$ & $182.422 * * *$ & $259.013 * * *$ \\
\hline & (438.006) & (276.626) & $(256.681)$ & $(182.032)$ & $(194.520)$ & $(136.080)$ & $(66.597)$ & $(59.274)$ \\
\hline Observations & 119 & 117 & 119 & 117 & 119 & 117 & 119 & 117 \\
\hline \multirow[t]{2}{*}{ R-squared } & 0.884 & 0.970 & 0.568 & 0.960 & 0.546 & 0.966 & 0.274 & 0.912 \\
\hline & (9) & (10) & (11) & (12) & (13) & (14) & (15) & (16) \\
\hline VARIABLES & \multicolumn{2}{|c|}{$\begin{array}{l}\text { Loans to nonfinancial } \\
\text { corporations }\end{array}$} & \multicolumn{2}{|c|}{$\begin{array}{l}\text { Loans to nonfinancial } \\
\text { corporations - short-term }\end{array}$} & \multicolumn{2}{|c|}{$\begin{array}{l}\text { Loans to nonfinancial } \\
\text { corporations - medium-term }\end{array}$} & \multicolumn{2}{|c|}{$\begin{array}{l}\text { Loans to nonfinancial corporations - } \\
\text { long-term }\end{array}$} \\
\hline Estimator & FMOLS & DOLS & FMOLS & DOLS & FMOLS & DOLS & FMOLS & DOLS \\
\hline \multirow[t]{2}{*}{ Central Bank External Assets } & $0.088 * * *$ & $0.070 * * *$ & 0.002 & 0.001 & $0.025 * * *$ & $0.022 * * *$ & $0.061 * * *$ & $0.047 * * *$ \\
\hline & $(0.009)$ & $(0.004)$ & $(0.002)$ & $(0.001)$ & $(0.002)$ & $(0.001)$ & $(0.007)$ & $(0.004)$ \\
\hline \multirow[t]{2}{*}{ Output } & $-2.591 * * *$ & $-4.609 * * *$ & $-0.493 * *$ & $-0.755 * * *$ & $-0.611 * * *$ & $-1.101 * * *$ & $-1.478 * *$ & $-2.753 * * *$ \\
\hline & $(0.874)$ & $(0.464)$ & $(0.198)$ & $(0.137)$ & $(0.213)$ & $(0.111)$ & $(0.718)$ & $(0.445)$ \\
\hline \multirow[t]{2}{*}{ Economic Sentiment Indicator } & 2.013 & $3.505 * * *$ & $-0.804 * * *$ & $-0.528 * * *$ & -0.030 & $0.512 * * *$ & $2.827 * * *$ & $3.521 * * *$ \\
\hline & $(1.254)$ & $(0.604)$ & $(0.285)$ & $(0.179)$ & $(0.306)$ & $(0.145)$ & $(1.030)$ & $(0.579)$ \\
\hline \multirow[t]{2}{*}{ Interest Rate } & $-18.978 *$ & $-22.813 * * *$ & 3.603 & $3.101 * *$ & $11.034 * * *$ & $11.410 * * *$ & $-33.650 * * *$ & $-37.324 * * *$ \\
\hline & $(10.960)$ & (4.418) & $(2.489)$ & (1.307) & (2.676) & (1.059) & (9.001) & (4.236) \\
\hline \multirow[t]{2}{*}{ Constant } & $839.791 * * *$ & $928.597 * * *$ & $383.488 * * *$ & $386.102 * * *$ & $192.647 * * *$ & $194.399 * * *$ & $264.461 * * *$ & $348.096 * * *$ \\
\hline & (95.063) & (39.745) & (21.587) & (11.755) & (23.214) & (9.531) & (78.071) & (38.106) \\
\hline Observations & 119 & 117 & 119 & 117 & 119 & 117 & 119 & 117 \\
\hline R-squared & 0.748 & 0.955 & 0.155 & 0.600 & 0.678 & 0.949 & 0.689 & 0.958 \\
\hline
\end{tabular}

Standard errors are in parentheses. $*$ denotes 10 percent significance level, $* *$ denotes 5 percent significance level, $* * *$ denotes 1 percent significance level. 